\title{
Density-dependent regulation of population size in colonial breeders: Allee and buffer effects in the migratory Montagu's harrier
}

\author{
Alvaro Soutullo • Rubén Limiñana • Vicente Urios • \\ Martín Surroca • Jennifer A. Gill
}

\begin{abstract}
Expanding populations offer an opportunity to uncover the processes driving spatial variation in distribution and abundance. Individual settlement decisions will be influenced by the availability and relative quality of patches, and by how these respond to changes in conspecific density. For example, conspecific presence can alter patch suitability through reductions in resource availability or territorial exclusion, leading to buffer effect patterns of disproportionate population expansion into poorer quality areas. However, conspecific presence can also enhance patch suitability through Allee effect processes, such as transmission of information about resources or improved predator detection and deterrence. Here, we explore the factors underlying the settlement pattern of a growing population of Montagu's harriers (Circus pygargus) in Spain. The population increased exponentially between 1981 and 2001, but stabilised between 2001 and 2004. This population increase occurred alongside a remarkable spatial expansion, with novel site use occurring prior to maximum densities in occu-
\end{abstract}

Communicated by Markku Orell

A. Soutullo $(\square) \cdot$ R. Limiñana $\cdot$ V. Urios

Estación Biológica Terra Natura (CIBIO-Fundación Terra

Natura), Universidad de Alicante, Apdo. correos 99,

Alicante 03080, Spain

e-mail: a.soutullo@gmail.com

M. Surroca

Centro de recuperación de Fauna "Forn del Vidre",

Generalitat Valenciana, Castellon, Spain

J. A. Gill

School of Biological Sciences, University of East Anglia, Norwich, NR4 7TJ, UK

pied sites being reached. However, no temporal trends in fecundity were observed and, within sites, average fecundity did not decline with increasing density. Across the population, variance in productivity did increase with population size, suggesting a complex pattern of density-dependent costs and benefits. We suggest that both Allee and buffer effects are operating in this system, with the benefits of conspecific presence counteracting density-dependent declines in resource availability or quality.

Keywords Allee effect · Buffer effect · Density dependence $\cdot$ Ideal despotic distribution $\cdot$ Ideal free distribution

\section{Introduction}

When choosing a site to settle, individuals need to consider both the quality of the sites available (in terms of environmental conditions, resource availability, the presence of predators and parasites, etc.) and the presence of conspecifics (Sutherland 1996; Newton 1998). The presence of conspecifics may either decrease or enhance the appeal of a site, with territorial species and colonial species occupying the extremes of this continuum (Stephens and Sutherland 1999). Thus, in a growing population, the pattern of settlement or patch colonisation and occupancy can be understood, reconstructed and predicted on the basis of these two factors: (1) if the suitability of a patch decreases with every new individual added to the patch, and individuals can choose to settle in any patch, then newcomers will prefer to settle in the most suitable patch at the time they arrive (with suitability being a function of 
site quality and the number of conspecifics already settled there); (2) if patches differ in quality and individuals arriving earlier prevent others from settling in the patch they occupy, then sites will be filled sequentially in order of decreasing quality; and (3) if individuals benefit from the presence of conspecifics, then the suitability of a patch changes with both the number of conspecifics and patch quality in a non-linear fashion; in such a scenario there is an optimal density at intermediate population sizes and, hence, individuals will prefer to settle in sites where, with their presence, density will be as close to optimal as possible.

In these three scenarios, when population size increases, rates of increase are expected to be greater in poor-quality than in good-quality sites. This phenomenon is known as the buffer effect (Brown 1969; Rosenzweig 1991; Sutherland 1996; Rodenhouse et al. 1997; Gill et al. 2001; Sutherland and Norris 2002). Buffer effects occur because while at low population sizes most animals occupy better-quality sites, when population density increases, an increasing proportion of the population is displaced into poorer-quality sites. The buffer effect is ecologically important because it describes the process underlying density-dependent changes in fecundity and mortality, and hence provides an insight into the mechanisms regulating population growth and abundance (Gill et al. 2001). It has been demonstrated in a wide range of taxa, illustrating a widespread link between increasing population density, distribution patterns across a habitat-quality gradient, and demography in animals (e.g. Krebs 1970; Halama and Dueser 1994; Ferrer and Donázar 1996; Rodenhouse et al. 1997; Fernández et al. 1998; Gill et al. 2001; Krüger and Lindström 2001; Sergio and Newton 2003; Kokko et al. 2004; Gunnarsson et al. 2005). Furthermore, buffer effects can be a major process influencing large-scale population regulation of migratory species (Gill et al. 2001; Gunnarsson et al. 2005).

Buffer effects can arise as a consequence of depletion driving individuals to exploit an increasing range of patches, or by competitive exclusion through interference or territoriality (Sutherland 1996). In such systems, individuals should seek to minimise the exploitation of resources by conspecifics. However, in colonial species, increasing colony size can provide advantages including transmission of information about food, earlier predator detection and higher defence efficiency (e.g. Wiklund and Andersson 1994; Arroyo et al. 2001; Serrano et al. 2005), all of which increases individual fitness. This kind of positive relationship between a component of individual fitness and either numbers or densities of conspecifics constitutes what is usually called an Allee effect (Allee et al. 1949; Sutherland 1996; Stephens and Sutherland 1999). Indeed, animal aggregations resulting from the benefits of conspecific presence are a direct product of the Allee effect (Stephens and Sutherland 1999). The Allee effect is thus a major driving force behind animal sociality, and the degree of sociality of a species might reflect the degree of severity of the Allee effects to which it is subject. Consequently, the spatial distribution of a species is, to a large degree, determined by the relative strength of buffer and Allee effects, which can in turn impact on many other aspects of the species' ecology (Stephens and Sutherland 1999). Therefore, when attempting to reconstruct the pattern of patch occupancy of a growing population, both the costs and benefits of conspecific presence should be considered.

Behavioural models can be used to deduce the behavioural decisions shaping patterns of patch occupancy and individual settlement and, thus, the kind of biological interactions (e.g. competition, cooperation, etc.) that regulate population expansions. These interactions produce different patterns of occupancy and settlement (Sutherland 1996; Newton 1998), and the relative importance of different types of interaction can be informed by observations of individual mortality and fecundity (Ferrer and Donázar 1996; Krüger and Lindström 2001; Sergio and Newton 2003). The effects of these interactions on fecundity and mortality can be modelled on the basis of three alternative behavioural models: the ideal free distribution, the ideal despotic distribution, and modifications of the ideal free distribution that take into account Allee effects (Sutherland 1996; Stephens and Sutherland 1999). As a population increases, density-dependent declines in fitness can arise from an increase in interference that leads to a relatively uniform decrease in site suitability (Ferrer and Donázar 1996; Rodenhouse et al. 1997; Fernández et al. 1998; Newton 1998; Krüger and Lindström 2001). This is independent of differences in site quality and will operate both in homogeneous and heterogeneous landscapes (in terms of site quality). In a heterogeneous landscape, the spatial distribution of individuals will resemble that described by the ideal free distribution, with animals locating themselves in those patches where the number of competing conspecifics and the quality of the site will provide the highest profit. In territorial species, and when a gradient in site quality exists, density-dependent fitness declines may result from individuals competing for better sites (Ferrer and Donázar 1996; Rodenhouse et al. 1997; Fernández et al. 1998; Newton 1998; Krüger and Lindström 2001; Kokko et al. 2004). In this case, individual behaviour is better described by the ideal despotic distribution 
(Sergio and Newton 2003; Kokko et al. 2004). The presence of newcomers does not decrease the suitability of the sites already occupied by the first ones to arrive or those that manage to secure high-quality sites for themselves through agonistic interactions. However, those that arrive later, or are unable to defend good sites, have to tolerate worse conditions. Hence, unlike the interference scenario, the average reward does differ between sites. Finally, in colonial species, where individuals benefit from the presence of conspecifics, reduced fitness is expected at low population sizes or densities. However, when population size increases, so will individual fitness increase, up to a point at which density-dependent competition counteracts the positive effects of density, and individual fitness starts to decline, as described by the Allee effect.

Here we evaluate whether the factors underlying the behavioural decisions and the settlement pattern of a growing population of Montagu's harriers (Circus pygargus) in Spain can be deduced from predictions about fecundity and density derived from these models. We predict that, at both the whole population level and at the level of the discrete breeding colonies that comprise the population, fecundity is expected to have decreased if competition with conspecifics has driven patch colonisation in the area. However, if territoriality rather than interference operated, then large differences in reproductive output are expected among pairs, with differences increasing with population size, as the best territories are expected to be occupied first (Brown 1969; Ferrer and Donázar 1996). By contrast, if reproductive output is increased when several pairs breed together, then, at the colony level, a non-linear relationship between density and reproductive parameters is expected, with fecundity remaining high and relatively stable at intermediate densities (Sutherland 1996; Stephens and Sutherland 1999). Above such optimal density (i.e., the density at which the number of offspring produced on average by an individual, $R_{0}$, is maximum), negative density-dependent effects would decrease individual fitness. Below it, decreased protection from a smaller colony would also decrease fitness. In terms of patch colonisation, if competition was the main driving force, then the number of pairs in a patch is not expected to have increased until most of the suitable patches in the study area were colonised. Therefore, the population is expected to have undergone a geographical expansion, but density in each patch is expected to have remained low. In contrast, if breeding harriers benefit from the presence of conspecifics, then birds are not expected to have colonised unoccupied patches until densities in the occupied ones have increased to levels where fecundity starts to decline.
Thus, while the population is expected to have expanded geographically, a sequential colonisation of patches is expected, with many suitable patches not yet colonised, and densities in occupied ones having increased significantly during the population growth, and then stabilised. Such densities are expected to vary depending on patch quality.

After a 20 -year-long increase, the population we studied has remained stable for the last 4 years at a size well below the carrying capacity estimated for the area it occupies (Limiñana et al. 2006). Thus, we also explore whether birds behavioural decisions can explain the stabilisation in population size.

\section{Materials and methods}

\section{The species}

The Montagu's harrier is a medium-sized migratory raptor. Birds breeding in Europe arrive from sub-Saharan Africa in early April (Clarke 1996). The species is considered monogamous although polygamy (both polygyny and polyandry) has occasionally been recorded (Cramp and Simmons 1980; Underhill-Day 1990; Arroyo 1996). In our study area, polygamy has not been recorded; hence, each nest found is related to a monogamous pair. First breeding occurs generally in the third calendar year in females and in the fourth in males (Studinka 1941; Cramp and Simmons 1980; Arroyo et al. 2004). Clutch size is typically 3 or 4 eggs, range 1-10 (Cramp and Simmons 1980; Arroyo et al. 2004). Mean productivity ranges from 1.40 to 2.75 fledglings per pair (Pandolfi and Giacchini 1991; Arroyo 1995; Castaño 1997; Corbacho et al. 1997; Koks et al. 2001; Limiñana et al. 2006; see Arroyo et al. 2004 for a review).

Although it is a semi-colonial species (Clarke 1996), some pairs breed solitarily. Arroyo (1995) found that most pairs in Madrid (Spain) nested in colonies. In other European regions, more than $55 \%$ of the populations breed in colonies (Clarke 1996). Despite Montagu's harriers being non-territorial (Pandolfi and Pino d'Astore 1992), conspecific aggression occurs, especially between males, and increases with colony size (Arroyo 1995). Individuals generally hunt far from nests (Cramp and Simmons 1980; Clarke 1996; Guixé 2002), and the main prey are insects, small passerines and mammals, and lizards, but they may also feed on lagomorphs (Schipper 1973; Hiraldo et al. 1975; Corbacho et al. 1995; Arroyo 1997; Sánchez and Calvo 1998). Across Europe, most populations breed in cereal crops, with some breeding in natural vegetation. In 
general, productivity is higher in natural habitats than in cereal crops (Arroyo et al. 2004; Limiñana et al. 2006). About 5,000 pairs breed in Spain (García and Arroyo 2003), with $90 \%$ of them breeding in cereal crops (Ferrero 1995).

\section{Study area}

This study was conducted in inland Castellon province (Valencia, north-eastern Spain; Fig. 1). Although Montagu's harriers have been found breeding in coastal Castellon for decades, they were first recorded breeding in inland Castellon in 1979 (about $20 \mathrm{~km}$ from the coastal population). Since 1981 the population has experienced a massive increase from the 3 pairs originally recorded, to the current breeding population that oscillates around 98 pairs (Limiñana et al. 2006). In inland Castellon, Montagu's harriers use sclerophyllous Mediterranean shrublands for nesting. The most abundant species are Kermes oak Quercus coccifera, gorse Ulex parviflorus and rosemary Rosmarinus officinalis, with dry crops (vine, olive, almond and cereals) interspersed (see Limiñana et al. 2006 for details). The productivity observed in this population is amongst the highest recorded for the species (Arroyo et al. 2004; Limiñana et al. 2006). In the early 1990 s, a new breeding population settled in the neighbouring Tarragona province, Catalonia, about $50 \mathrm{~km}$ from the place where our population first settled (Pomarol and Bonfil 2001).

Causes of the growth of this population are uncertain. Possible explanations include both changes in the breeding and the wintering grounds. No major environmental changes have been observed in our study area during the last 20 years. However, the area does support a rich supply of prey for the species, as well as appropriate habitat for nesting and low human pressure, which probably explains the massive population increase observed soon after the first breeding pairs settled there (Limiñana et al. 2006). Hence, although the reasons that lead to the settlement of the first harriers in our study area are unclear (especially why they had not established there before), the reasons behind the population growth seem to be more evident: prey availability and good conditions for nesting. There is evidence of natal philopatry in Montagu's harriers (Clarke 1996), and in our study area several individuals marked there as chicks have subsequently been seen breeding there as adults. Hence, once the first individuals settled there, a positive feedback between the number of breeding pairs and the number of birds returning to breed may have contributed to the increased local abundance. Furthermore, analyses carried out elsewhere have shown that there is a positive relationship between the number of fledglings produced in an area and the number of birds settling there in subsequent years (Arroyo et al. 2002).

\section{Data and statistical methods}

The Montagu's harrier population in inland Castellon has been monitored by the Conselleria de Territorio y Vivienda of the Generalitat Valenciana during the last 25 years. Data on population size (i.e., number of pairs) are available since 1981, and data on breeding biology since 1989. Surveys covering an area of ca. $1,350 \mathrm{~km}^{2}$ are conducted every year during the breeding season (April-July). The number of pairs in each district is recorded, and accessible nests (approximately half of all nests) are regularly visited to monitor breeding parameters (clutch size, brood size and productivity). See Limiñana et al. (2006) for details of the study area and surveys.

To estimate changes in the total area occupied by the population since 1981, for each year we calculated the minimum convex polygon encompassing all the monitored nests. The Nonlinear Estimation module within the package Statistica was used to compute the relationship between year and population size until 2001, when population size stabilised.

To test predictions of the ideal free and despotic distributions, temporal trends in fecundity for the whole population were explored using Spearman's correlations. For each variable, mean and coefficient of variation $(\mathrm{CV})$ were calculated. Variations in fecundity

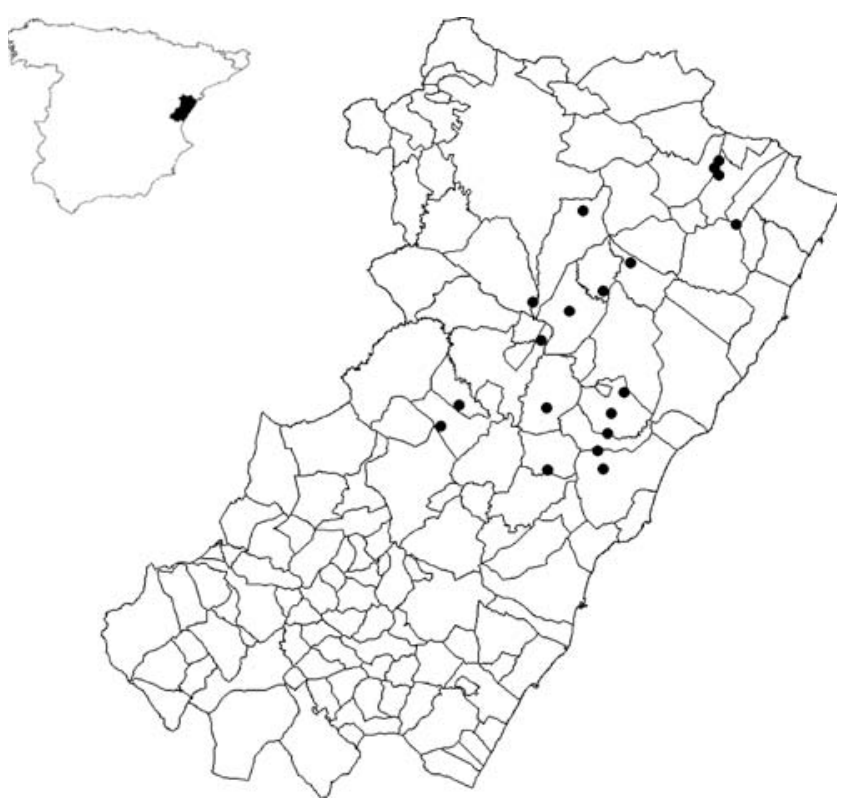

Fig. 1 Map of Castellon province, Spain, showing districts and breeding colonies (dots) of Montagu's harriers (Circus pygargus) 
were evaluated using the $\mathrm{CV}$ to avoid biases associated with increasing sample sizes (e.g. Ferrer and Donázar 1996). We also studied the relationship between density and fecundity in 4 of the 19 breeding colonies within our study area to test predictions based on the Allee effect. We chose colonies for which colony size varied enough to test for trends (i.e., at least six different colony sizes). The study area encompasses large expanses of unsuitable habitat for breeding harriers (although the suitable habitat constitutes the landscape matrix rather than patches within it), thus, following Limiñana (2004), reproductive colonies were delimited on the basis of the presence of discrete areas of suitable habitat for breeding separated by unsuitable habitat including forests, dry croplands and human settlements. As colonies are defined on the basis of the area they occupy ("patches"), changes in colony size are equivalent to changes in density in the patch, as the area corresponding to a given colony remained largely unchanged during the study period. For each colony linear and quadratic relationships between density and fecundity were analysed using the Curve Estimation module in SPSS. Data on all colonies were then pooled together to construct a General Linear Model using the GLM module in SPSS, with density as a continuous covariate and colony as a fixed factor. We used the Kruskal-Wallis test to compare the densities attained in the different colonies.

Both within-patch relationships between density and fecundity, and temporal trends in fecundity for the whole population, were evaluated using the following parameters: clutch size (number of eggs laid by each pair; only pairs with complete clutches were considered); brood size (number of hatchlings per pair; only pairs with at least one hatchling were considered); productivity (number of fledglings per pair); hatching rate (percentage of hatchlings per egg laid by each pair); fledging rate (percentage of fledglings per hatchling); and percentage of fledglings per egg laid by each pair. In order to quantify trends in the performance of birds in the upper and lower extremes of the distribution of productivity, temporal trends in the upper and lower quartiles were also explored.

\section{Results}

Between 1981 and 2001 the population size increased exponentially, and has remained stable since then (Fig. 2, Table 1). A marked increase in the area occupied by the population was simultaneously observed, from less than $5 \mathrm{~km}^{2}$ in 1981 to $1,052 \mathrm{~km}^{2}$ in 2004.

\section{Behavioural processes influencing demography}

The costs and benefits of conspecific presence were explored by assessing demographic trends throughout the population expansion. At the population level, no temporal trend was observed in any of the measures of fecundity we analysed ( $P>0.29$ in all cases; Table 1$)$. The same is true at the colony level. Although marked increases in density with time were observed in three of the four colonies studied in detail (Fig. 3), none of the breeding parameters analysed showed a significant relationship with density (Table 2). The lack of significant linear or quadratic relationships does not provide direct support for any of the behavioural models.

In contrast, although there was no temporal trend in the productivity of the $25 \%$ of the population experiencing the lowest productivity (rho $=-0.30, n=15$,
Fig. 2 Exponential increase of a breeding population of Montagu's harriers in Spain. Dots indicate the number of pairs observed each year. The solid line represents the exponential growth model fitted to the data until 2001 (number of pairs $=\mathrm{exp}$ (-373.71+0.1891 × year), $F_{1,19}=295.64, P<0.0001$, $\left.R^{2}=0.94\right)$, when population size stabilised. The dotted line indicates the minimum convex polygon area including the nests recorded each year

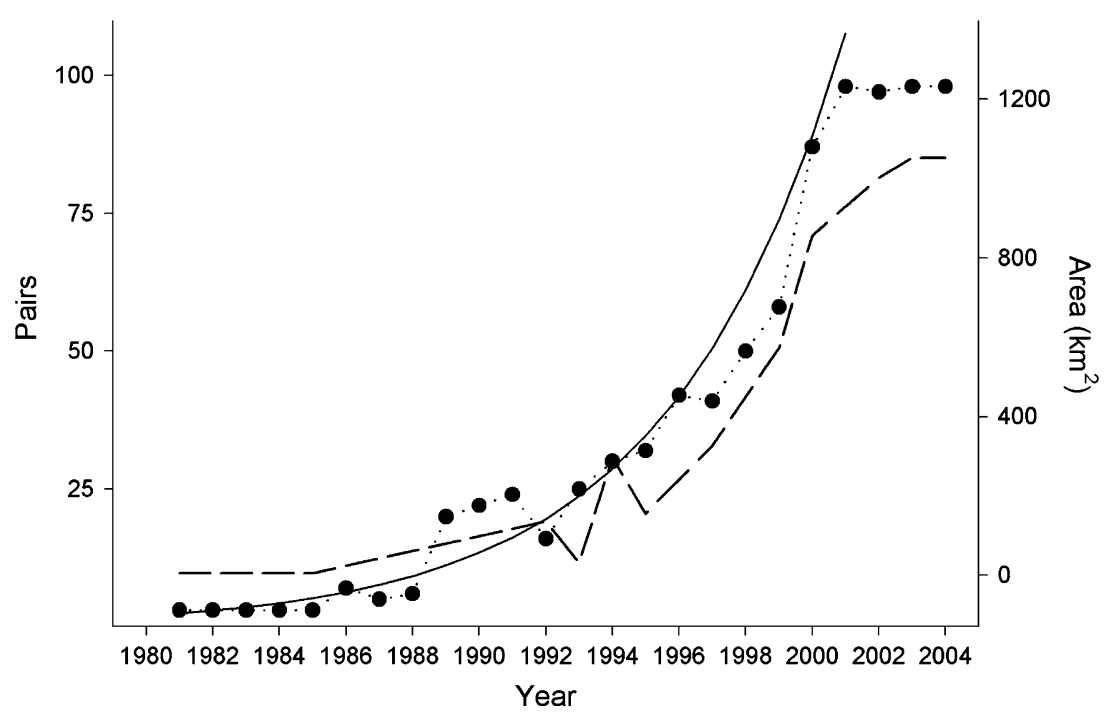


Table 1 Demographic and breeding parameters of an increasing population of Montagu's harriers (Circus pygargus) in Spain. Note that not all the monitored nests provided data on all parameters

\begin{tabular}{|c|c|c|c|c|c|c|c|c|c|c|c|c|c|c|}
\hline \multirow[t]{2}{*}{ Year } & \multirow{2}{*}{$\begin{array}{l}\text { Number } \\
\text { of pairs }\end{array}$} & \multirow{2}{*}{$\begin{array}{l}\text { Monitored } \\
\text { nests }\end{array}$} & \multicolumn{2}{|c|}{ Clutch size } & \multicolumn{2}{|c|}{ Brood size } & \multicolumn{2}{|c|}{ Productivity } & \multicolumn{2}{|c|}{ Hatching rate } & \multicolumn{2}{|c|}{ Fledgling rate } & \multicolumn{2}{|c|}{ Fledglings/egg } \\
\hline & & & Mean & $\mathrm{CV}$ & Mean & $\mathrm{CV}$ & Mean & $\mathrm{CV}$ & Mean & $\mathrm{CV}$ & Mean & $\mathrm{CV}$ & Mean & $\mathrm{CV}$ \\
\hline 1981 & 3 & - & - & - & - & - & - & - & - & - & - & - & - & - \\
\hline 1982 & 3 & - & - & - & - & - & - & - & - & - & - & - & - & - \\
\hline 1983 & 3 & - & - & - & - & - & - & - & - & - & - & - & - & - \\
\hline 1984 & 3 & - & - & - & - & - & - & - & - & - & - & - & - & - \\
\hline 1985 & 3 & - & - & - & - & - & - & - & - & - & - & - & - & - \\
\hline 1986 & 7 & - & - & - & - & - & - & - & - & - & - & - & - & - \\
\hline 1987 & 5 & - & - & - & - & - & - & - & - & - & - & - & - & - \\
\hline 1988 & 6 & - & - & - & - & - & - & - & - & - & - & - & - & - \\
\hline 1989 & 20 & 16 & 4.21 & 21.14 & 3.81 & 25.72 & 2.85 & 28.07 & 85.67 & 18.69 & 79.50 & 22.79 & 67.83 & 28.66 \\
\hline 1990 & 22 & - & - & - & - & - & - & - & - & - & - & - & - & - \\
\hline 1991 & 24 & 21 & 4.33 & 16.86 & 3.81 & 19.69 & 2.60 & 19.62 & 85.28 & 16.50 & 75.28 & 26.38 & 63.75 & 28.60 \\
\hline 1992 & 16 & 10 & 4.20 & 21.90 & 3.75 & 23.73 & 2.90 & 47.24 & 88.33 & 14.96 & 84.38 & 22.04 & 74.58 & 26.78 \\
\hline 1993 & 25 & 13 & 4.14 & 16.67 & 3.60 & 15.28 & 3.08 & 48.70 & 88.75 & 14.82 & 100.00 & 0.00 & 88.75 & 14.82 \\
\hline 1994 & 30 & 10 & 4.57 & 17.29 & 3.00 & 19.33 & 3.20 & 19.69 & 65.95 & 14.80 & 100.00 & 0.00 & 65.95 & 14.78 \\
\hline 1995 & 32 & 15 & 4.10 & 13.90 & 3.22 & 25.78 & 2.80 & 33.57 & 75.21 & 18.59 & 79.17 & 32.80 & 60.21 & 37.50 \\
\hline 1996 & 42 & 20 & 4.57 & 20.57 & 3.61 & 28.81 & 2.75 & 57.45 & 81.21 & 28.21 & 94.09 & 10.84 & 75.76 & 28.52 \\
\hline 1997 & 41 & 19 & 4.37 & 16.48 & 3.79 & 18.73 & 3.00 & 45.67 & 86.46 & 18.63 & 79.69 & 46.13 & 66.46 & 49.56 \\
\hline 1998 & 50 & 21 & 4.44 & 19.37 & 3.67 & 33.79 & 2.90 & 56.55 & 82.31 & 27.91 & 88.98 & 27.74 & 71.57 & 38.89 \\
\hline 1999 & 58 & 21 & 4.19 & 17.90 & 3.48 & 31.03 & 2.15 & 82.79 & 81.33 & 31.56 & 78.33 & 46.51 & 59.67 & 56.08 \\
\hline 2000 & 87 & 42 & 4.67 & 20.56 & 4.19 & 23.39 & 3.14 & 50.96 & 88.53 & 18.81 & 87.22 & 18.57 & 76.61 & 24.53 \\
\hline 2001 & 98 & 44 & 4.31 & 18.10 & 3.30 & 32.42 & 2.09 & 83.73 & 76.56 & 31.27 & 93.33 & 27.18 & 69.89 & 42.77 \\
\hline 2002 & 97 & 45 & 4.13 & 20.58 & 3.66 & 25.68 & 2.78 & 54.68 & 83.06 & 28.35 & 84.14 & 32.08 & 71.45 & 38.31 \\
\hline 2003 & 98 & 52 & 4.34 & 22.35 & 3.68 & 23.91 & 2.79 & 51.97 & 80.07 & 33.31 & 82.48 & 32.31 & 69.62 & 38.14 \\
\hline 2004 & 98 & 51 & 3.97 & 25.19 & 3.48 & 28.74 & 2.78 & 44.96 & 87.12 & 18.90 & 84.82 & 21.59 & 73.74 & 28.04 \\
\hline
\end{tabular}

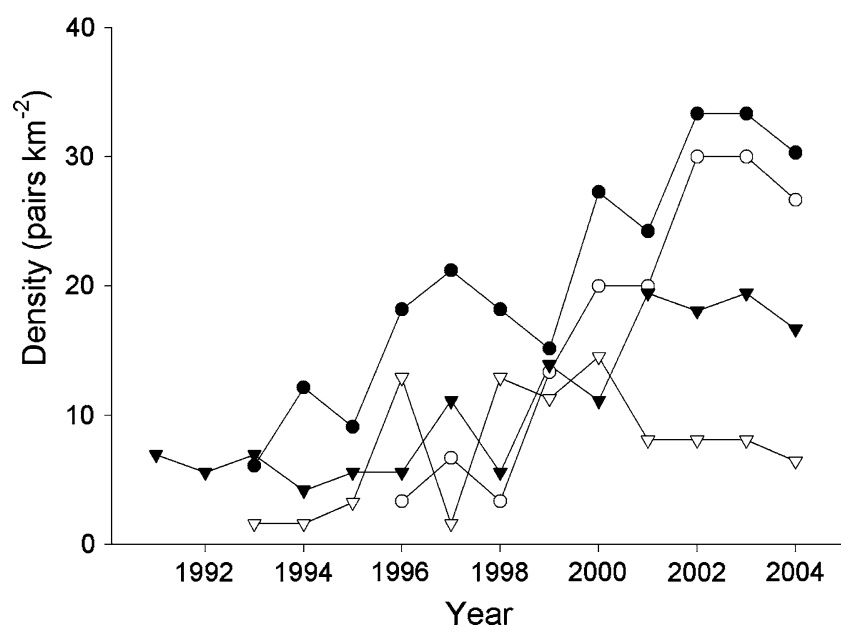

Fig. 3 Temporal trends in density in four breeding colonies of Montagu's harriers in Spain

$P=0.274$ ), the productivity of the birds in the upper $25 \%$ did increase significantly (rho $=0.63, n=15$, $P=0.012$ ), in line with predictions based on the Allee effect (Fig. 4). Actually, only for hatching rate (rho $=0.74, n=15, P=0.002$ ) and productivity (rho $=0.56$, $n=15, P=0.031$ ) did differences among pairs (i.e., $\mathrm{CV}$ ) increase with time $(P>0.15$ in all other cases; Table 1$)$. Both hatching rate and productivity are, however, highly correlated (rho=0.76, $n=15, P=0.001$ ).
Table 2 Relationships between fecundity and density in four reproductive colonies of Montagu's harriers in Spain. Densities in these colonies ranged between low to intermediate levels of 1.6 and 33.3 pairs $/ \mathrm{km}^{2}$

\begin{tabular}{lllllllll}
\hline & \multicolumn{2}{l}{ Density } & & & \multicolumn{2}{l}{ Colony } \\
\cline { 2 - 4 } & $F$ & $d f$ & $P$ & $F$ & & $d f$ & $P$ \\
\hline Clutch size & 0.04 & 1,38 & 0.85 & 1.28 & & 3,38 & 0.30 \\
Brood size & 0.17 & 1,40 & 0.68 & 0.30 & & 3,40 & 0.82 \\
Productivity & 2.87 & 1,41 & 0.10 & 1.49 & & 3,41 & 0.23 \\
Hatching rate & 0.91 & 1,38 & 0.77 & 0.36 & & 3,38 & 0.79 \\
Fledgling rate & 0.16 & 1,39 & 0.69 & 1.14 & & 3,39 & 0.35 \\
Fledglings/egg & 0.13 & 1,36 & 0.72 & 0.93 & & 3,36 & 0.44 \\
\hline
\end{tabular}

Patch colonisation

Across the four colonies studied in detail, significant differences in the maximum density attained were observed $\left(\chi^{2}=16.16, d f=3, P<0.001\right)$. However, no differences in fecundity were observed (Table 2), suggesting that some patches allow reproductive output to remain high over a wider range of optimal densities. Figure 5 shows the population increase observed in each district and the sequential colonisation of new patches. Fluctuations in densities in occupied patches probably reflect year-to-year changes in food availability and climatic conditions. 


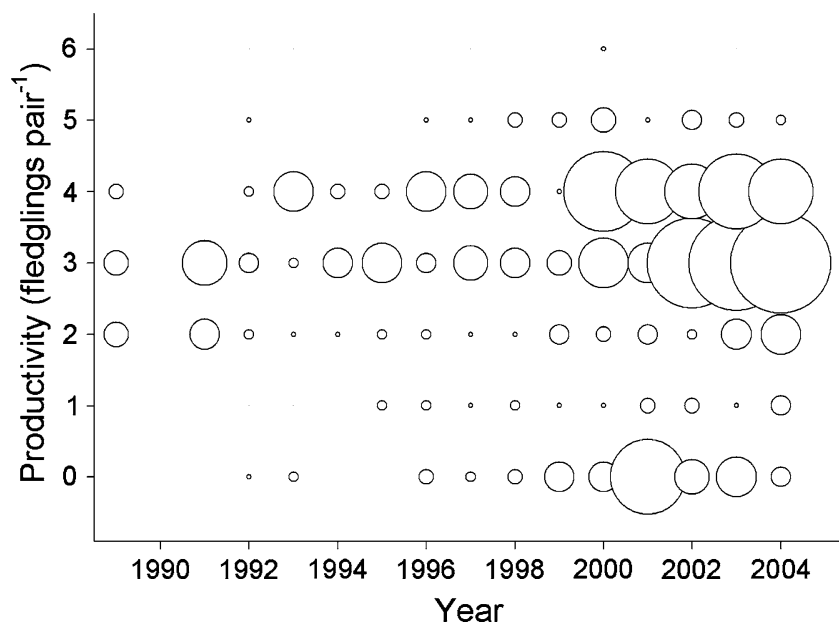

Fig. 4 Productivity observed in Montagu's harriers breeding in Spain. Size of circles represents the number of nests in each productivity class (ranging from 1 to 19 nests). Note that the number of nests monitored changed from year to year and that the range of productivity values observed increased with time

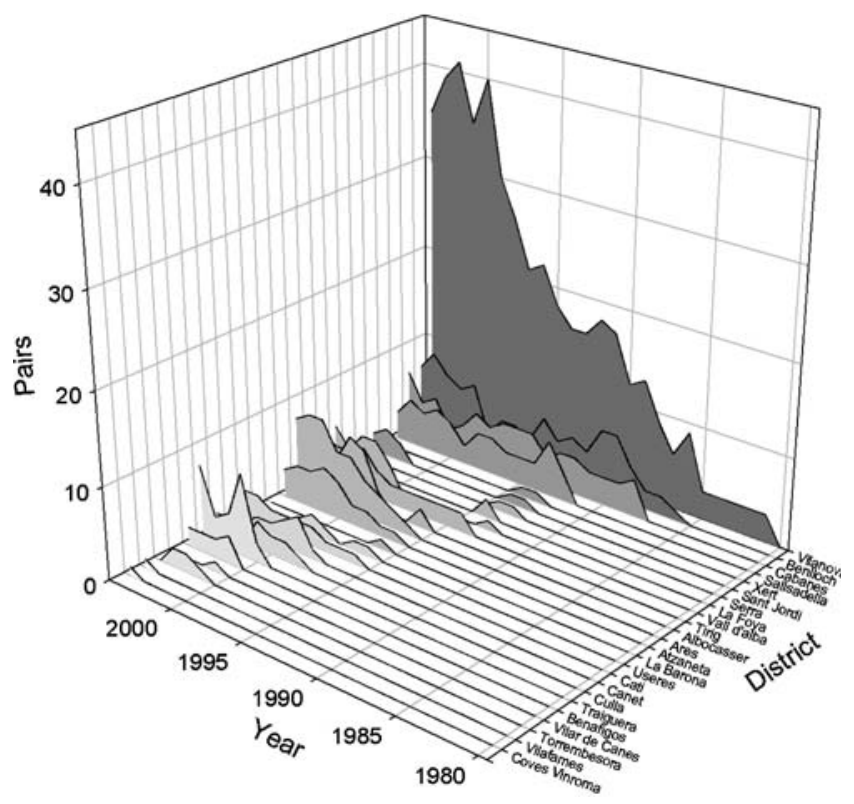

Fig. 5 Population increases of Montagu's harriers within 24 districts in Castellon province, Spain. Districts can include more than one breeding colony (e.g. Vilanova includes three). Data are from Bort-Cubero (2004), so there might be slight differences with our data in the number of pairs observed each year

\section{Discussion}

Despite an abrupt stabilisation in population size after a 20-year-long period of exponential increase, we did not observe declines in any of the measures of fecundity we evaluated. This is probably because, together with the increase in size, the population has undergone a remarkable spatial expansion. Differences among pairs in hatching rate and productivity increased with time, but no temporal trends were observed in the other four parameters evaluated. Both are highly correlated and, as clutch size remained constant throughout the study period, it seems reasonable to assume that the increment in the variability in productivity is actually a consequence of the increment in the variability of hatching rate.

Variation in hatching rates may be the result of several factors, such as differing levels of predation or differences in environmental conditions or individual experience (e.g. Arcá and Sammuri 1983; Viñuela 1993; Corbacho et al. 1997; Sergio and Newton 2003). However, the fact that hatching rate variability increased while the mean value remained constant indicates that the temporal trend in variability is not only the result of the fecundity of some pairs having decreased, but also of the fecundity of others having improved. This is supported by the observation that while the percentage of unsuccessful nests increased with time (Limiñana et al. 2006; see Fig. 4), average productivity remained constant. While the low productivity of some pairs may be a consequence of those birds being forced to locate in poor-quality sites (and possibly be more exposed to predation), the improvement in the conditions experienced by others may be a consequence of, for example, a larger number of pairs in the patch decreasing the likelihood of nests being predated (e.g. Arroyo et al. 2001; Serrano et al. 2005). Indeed, the productivity of the most productive fraction of the population increased with population size (Fig. 4).

These observations do not support the predictions based on the classic ideal free and ideal despotic distributions (as fecundity did not decrease with an increase in density), but are rather in line with predictions that take into account the Allee effect. This is reinforced by the fact that no relationship between density and any of the reproductive parameters analysed was observed at the colony level, suggesting that, in our study area, the relationship between fecundity and density is not linear and monotonic, as classic models suggest. The sequential pattern of patch colonisation observed is also in line with predictions based on the Allee effect; while the population has expanded geographically, probably many suitable patches have not been colonised yet, but density in the occupied patches has increased significantly and stabilised at intermediate levels with no decline in fecundity.

Although Fernández et al. (1998) suggest that the distribution pattern of social breeders is most likely 
shaped by interference (and hence better described by the ideal free distribution), this does not seem to be the whole story here. Actually, the abrupt stabilisation in population size we observed might suggest that individuals simply chose sites at random, with the net rate of population increase remaining stable until all territories were full, and then declining abruptly (Hawkins and Berryman 2000). However, this is not supported by our observations on individual fecundity, as many individuals experienced increasing fecundity as population size increased, which is not expected if birds choose sites at random unless they simultaneously benefit from the presence of conspecifics. Hence, we suggest that in our study area the stabilisation is a consequence of the interplay between Allee and buffer effects: the maximum number of individuals a patch can sustain is determined by patch quality, but the density of conspecifics in the occupied patches determines whether a new patch is colonised or not, and both density in occupied patches and the number of occupied patches determines population size. However, the factors influencing the decision of whether to colonise a new patch or settle in an occupied one need not be the same as those influencing the decision of which one of the unoccupied patches to colonise (actually the order of colonisation may even be random, or influenced by other factors such as the distance to other occupied patches). Hence, while site quality and conspecific density play a key role in the first case, other factors may be more important in the second one (including considerations regarding whether site quality is public information or not), and thus, which patches have been colonised, and the order in which they were colonised need not reflect their quality. In such a scenario, fecundity may not decline noticeably until all suitable patches within reach are colonised and reproductive output starts to decline because of crowding, but patch colonisation will occur sequentially, as unoccupied patches are not colonised until occupied ones start to become crowded.

As described in Fig. 6, we suggest that the relationship between fecundity and density can be divided into four stages in colonial breeders: an initial stage where fecundity increases with density, a second stage where fecundity remains relatively stable $\left(D_{\text {optimal }}\right)$, a third stage $(O)$ where fecundity decreases with density but it is still higher than that of a pair breeding alone, and a fourth one $(C)$ where only the negative effects of density are observed (i.e., classic density-dependence). During the second stage $\left(D_{\text {optimal }}\right)$, individual reproductive output is highest (i.e., $R_{0}$ is maximum), so from an individual perspective density is optimal.

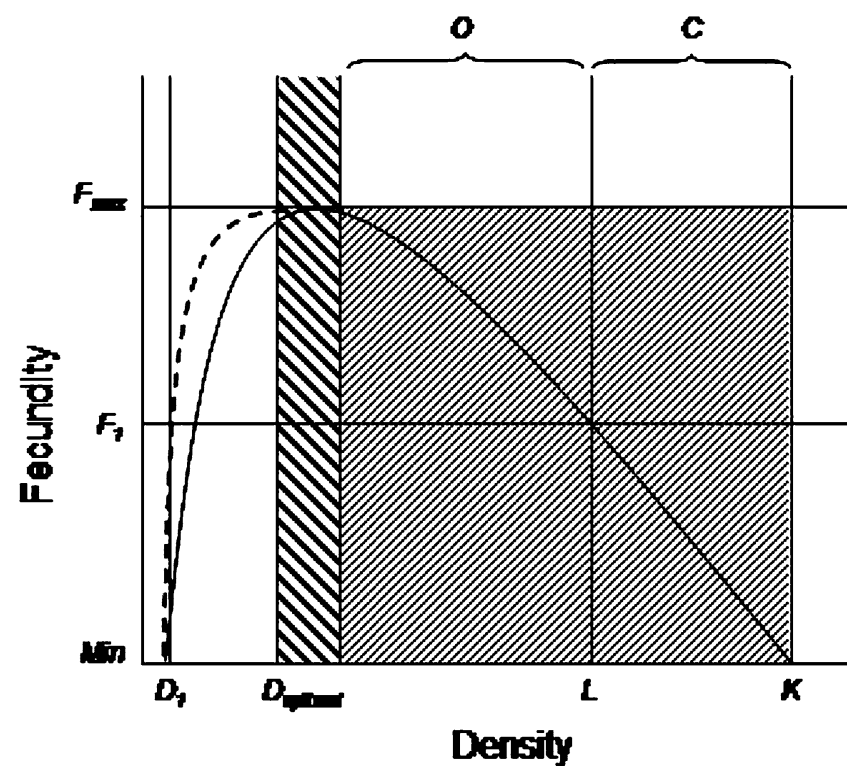

Fig. 6 A non-linear relationship between fecundity and density in colonial breeders. $F_{\max }$ indicates the maximum number of offspring that an individual can produce on average under ideal conditions in a given site. Fecundity initially increases with density and then declines. Different rates of change in fecundity are possible, only two are shown: rapid (dotted line) and moderate (continuous line). $D_{1}$ indicates a density of one pair and $F_{1}$ the fecundity of a pair breeding alone. $K$ represents the carrying capacity of the site, and Min the fecundity at $K$. $D_{\text {optimal }}$ (represented by the hatched band) indicates the range of densities at which $F_{\max }$ can be attained. Above that density, sites are supersaturated. Before they reach $K$, two different phases can be distinguished: $O$ (overshoot), which represents the range of densities at which the mean fecundity experienced by individuals is lower than optimal but still higher than in unoccupied sites, and $C$ (classic density-dependence), where no advantage due to conspecific presence is obtained, and only the negative effects of density are experienced. $L$ represents the limit between these phases. Once $L$ has been reached in a site, and if there are still unoccupied sites available nearby, newcomers will do better by settling somewhere else than in the supersaturated site. The phase $C$ is expected to be reached only when all reachable sites in the region are supersaturated up to $L$. The shaded area indicates the population sizes at which negative effects of density are experienced

In an expanding population, this means that irrespective of the quality of the unoccupied patches available, individuals are not expected to settle in unoccupied patches until density in the occupied patches is above optimal (with the range of optimal densities depending in turn on patch quality). Furthermore, individuals are expected to keep on settling in occupied patches even when the optimal density has been exceeded and fecundity has started to decline $(O)$. Only when the fecundity experienced is lower than that experienced in unoccupied patches (i.e., density is higher than $L$ ), are the newcomers expected to settle in these patches (see Fig. 6). However, once the 
first individuals have settled in a patch, the advantages of occupying a patch where density is above optimal will start to decline and the disadvantages will subsequently become increasingly larger than occupying patches with sub-optimal density. Hence, as far as patches with sub-optimal density (or empty) are available, density in the occupied ones is not expected to elevate beyond $L$.

This spatial dynamics may explain (at least partially) the observed stabilisation in our study area. Once the density in the occupied patches approached $L$, and as far as there were still suitable patches available in nearby Catalonia (as described in Materials and methods), newcomers probably experienced better conditions settling in those unoccupied patches, than in occupied patches within our study area. Hence, we suggest that the stabilisation we observed is actually a consequence of our scale of analysis (i.e., us monitoring just a fraction of the actual breeding population-see Camus and Lima 2002). At a regional scale the population is still increasing, but it is currently stable in the area we studied, which may actually be operating as a source of individuals for other areas (see Murdoch 1994). Only when all suitable patches in the region have been colonised and filled to a density close to $L$, should fecundity start to decline noticeably (see Fig. 6). Thus, the temporary stabilisation we observed is probably a result of changes in demographic parameters that stem from the interplay between buffer and Allee effects, with the suitability of a site being not simply a function of its quality in terms of resources and environmental conditions, but a more complex function of the number of conspecifics in a site and site quality.

Acknowledgments We are very grateful to Aeropuerto de Castellon for support and funding. We are thankful to Beatriz Arroyo, Luis Cadahía and Carlos Passos for insightful discussions of these ideas. A great part of the data presented here come from the monitoring and conservation programme of Montagu's harrier in Castellon conducted by the Generalitat Valenciana since 1988. These data have been provided by D.G. de Gestión del Medio Natural (Consellería de Territorio y Vivienda). Thanks are due to Pepe Durall, Sara Ferreras, Juan Jiménez, Stephan Miralles, Juanjo Palomo, Pepe Rovira, Miguel Ángel Solís and Ramón Prades for their help. We are particularly grateful to Liberto Villaroya and Anita. R.L. has a graduate fellowship from the Generalitat Valenciana. This paper is part of his $\mathrm{PhD}$ thesis at the Universidad de Alicante.

\section{References}

Allee WC, Emerson AE, Park O, Park T, Schmidt KP (1949) Principles of animal ecology. Saunders, Philadelphia

Arcá G, Sammuri G (1983) Biologia riproduttiva e status dell'albanella minore nella Maremma Tosco-Laziale. Dati preliminary. IIth Convego Italiano di Ornitologia, Parma pp 7-9
Arroyo BE (1995) Breeding ecology and nest dispersion of Montagu's Harrier Circus pygargus in Central Spain. $\mathrm{PhD}$ thesis, University of Oxford, Oxford

Arroyo B (1996) A possible case of polyandry in Montagu's Harrier. J Raptor Res 30:100-102

Arroyo BE (1997) Diet of Montagu's Harrier Circus pygargus in central Spain: analysis of temporal and geographical variation. Ibis 139:664-672

Arroyo B, Mougeot F, Bretagnolle V (2001) Colonial breeding and nest defence in Montagu's Harrier (Circus pygargus). Behav Ecol Sociobiol 50:109-115

Arroyo BE, García JT, Bretagnolle V (2002) Conservation of the Montagu's Harrier (Circus pygargus) in agricultural areas. Anim Conserv 5:283-290

Arroyo BE, Garcia JT, Bretagnolle V (2004) Montagu's Harrier. BWP Update 6:41-55

Bort-Cubero JV (2004) La colonización del aguilucho cenizo (Circus pygargus) en el interior de la provincia de Castellon (1980-2004). VIII Reunión del Grupo Ibérico de Aguiluchos, Madrid. Available at: http://www.cocn.tarifainfo.com/ ria04/ponencias/ppjbort/ponen.html

Brown JL (1969) Buffer effect and productivity in tit populations. Am Nat 103:347-354

Camus PA, Lima M (2002) Populations, metapopulations, and the open-closed dilemma: the conflict between operational and natural population concepts. Oikos 97:433-438

Castaño JP (1997) Fenología de puesta y parámetros reproductivos en una población de aguilucho cenizo (Circus pygargus) en el Campo de Montiel. Ardeola 44:51-59

Clarke R (1996) Montagu's Harrier. Arlequin, Chelmsford

Corbacho C, Muñoz A, Bartolomé P (1995) Espectro trófico del Aguilucho cenizo Circus pygargus en Extremadura. Alytes 7:441-448

Corbacho C, Sánchez JM, Sánchez A (1997) Breeding biology of Montagu's Harrier Circus pygargus L. in agricultural environments of southwest Spain; comparison with other populations in the western Paleartic. Bird Study 44:166-175

Cramp S, Simmons KEL (eds) (1980) The birds of the western Palaearctic, vol 2. Oxford University Press, Oxford

Fernández C, Azkona P, Donázar JA (1998) Density-dependent effects on productivity in the griffon vulture Gyps fulvus: the role of interference and habitat heterogeneity. Ibis 140:64-69

Ferrer M, Donázar JA (1996) Density-dependent fecundity by habitat heterogeneity in an increasing population of Spanish imperial eagles. Ecology 77:69-74

Ferrero JJ (1995) La población ibérica de Aguilucho cenizo ( Circus pygargus). Alytes 7:539-560

García JT, Arroyo B (2003) Aguilucho cenizo, Circus pygargus. In: Martí R, Del Moral JC (eds) Atlas de las Aves Reproductoras de España. Dirección General de Conservación de la Naturaleza - Sociedad Española de Ornitología, Madrid pp 178-179

Gill JA, Norris K, Potts PM, Gunnarsson TG, Atkinson PW, Sutherland WJ (2001) The buffer effect and large-scale population regulation in migratory birds. Nature 412:436-438

Guixé D (2002) Resultats de la caracterizació i radio-seguiment de la colònia d'esparver cendrós (Circus pygargus) d'Anglesola (Lleida). Informe para la Generalitat de Catalunya

Gunnarsson TG, Gill JA, Petersen A, Appleton GF, Sutherland WJ (2005) A double buffer effect in a migratory shorebird population. J Anim Ecol 74:965-971

Halama KJ, Dueser RD (1994) Of mice and habitats: tests for density-dependent habitat selection. Oikos 69:107-114

Hawkins BA, Berryman AA (2000) Site-dependent regulation of population size: comment. Ecology 81:1166-1168 
Hiraldo F, Fernández F, Amores F (1975) Diet of the Montagu's Harrier (Circus pygargus) in southwestern Spain. Doñana Acta Vertebrata 2:25-55

Kokko H, Harris MP, Wanless S (2004) Competition for breeding sites and site-dependent population regulation in a highly colonial seabird, the common guillemot Uria aalge. J Anim Ecol 73:367-376

Koks B, van Scharenburg K, Visser EG (2001) Grauwe Kiekendieven Circus pygargus in Nederland: balanceren tussen hoop en vrees. Limosa 74:121-136

Krebs JR (1970) Regulation of numbers in the Great Tit (Aves: Passeriformes). J Zool 162:317-333

Krüger O, Lindström J (2001) Habitat heterogeneity affects population growth in goshawk Accipiter gentilis. J Anim Ecol 70:173-181

Limiñana R (2004) Biología reproductiva del aguilucho cenizo (Circus pygargus) en el interior de la provincia de Castellon. M.Sc. Dissertation. Universidad de Alicante, Alicante

Limiñana R, Surroca M, Miralles S, Urios V, Jiménez J (2006) Twenty three-year population trend and breeding biology of Montagu's Harrier Circus pygargus in a natural vegetation site in Northeast Spain. Bird Study (in press)

Murdoch WW (1994) Population regulation in theory and practice. Ecology 75:271-287

Newton I (1998) Population limitation in birds. Academic, San Diego

Pandolfi M, Giacchini P (1991) Distribuzione e successo riproduttivo di albanella minore, Circus pygargus, nelle Marche. Riv Ital Ornitol 61:25-32

Pandolfi M, Pino d'Astore PR (1992) Aggressive behaviour in Montagu's Harrier (Circus pygargus) during the breeding season. Boll Zool 59:57-61

Pomarol M, Bonfil J (2001) L'esparver cendrós a Catalunya. Bioma 6:32-33
Rodenhouse NL, Sherry TW, Holmes RT (1997) Site-dependent regulation of population size: a new synthesis. Ecology 78:2025-2042

Rosenzweig ML (1991) Habitat selection and population interactions: the search for mechanism. Am Nat 137:S5-S28

Sánchez JA, Calvo JF (1998) Importance of birds and potential bias in food habit studies of Montagu's Harriers (Circus pygargus) in Southeastern Spain. J Raptor Res 32:254-256

Schipper WJA (1973) A comparison of prey selection in sympatric harriers (Circus) in Western Europe. Gerfaut 63:17-120

Sergio F, Newton I (2003) Occupancy as a measure of territory quality. J Anim Ecol 72:857-865

Serrano D, Oro D, Ursúa E, Tella JL (2005) Colony size selection determines adult survival and dispersal preferences: Allee effects in a colonial bird. Am Nat 166:E22-E31

Stephens PA, Sutherland WJ (1999) Consequences of the Allee effect for behaviour, ecology and conservation. Trends Ecol Evol 14:401-405

Studinka L (1941) The habits and plumages of Montagu's Harrier. Aquila 46-49:247-268

Sutherland WJ (1996) From individual behaviour to population ecology. Oxford University Press, Oxford

Sutherland WJ, Norris K (2002) Behavioural models of population growth rates: implications for conservation and prediction. Philos Trans R Soc B 357:1273-1284

Underhill-Day JC (1990) The status and breeding biology of Marsh Harrier Circus aeruginosus and Montagu's Harrier Circus pygargus in Britain since 1900. PhD thesis, National Council for Academic Awards

Viñuela J (1993) Variación en la fecha de puesta de una población de Milano Negro Milvus migrans. Efecto de la experiencia de los reproductores. Ardeola 40:55-63

Wiklund CG, Andersson M (1994) Natural selection of colony size in a passerine bird. J Anim Ecol 63:765-774 